\title{
Ética e pesquisa em educação: entre a regulação e a potencialidade reflexiva da formação
}

\author{
Ethics and education research: between regulation and the \\ reflexive potential of training
}

Ética y pesquisa en educación: entre la regulación y la
potencialidad reflexiva de la formación

\author{
MÓNICA DE LA FARE* \\ ISABEL CRISTINA DE MOURA CARVALHO** \\ MARCOS VILLELA PEREIRA****
}

\begin{abstract}
RESUMO
Este artigo apresenta uma pesquisa exploratória que busca contribuir com os debates sobre ética e pesquisa no contexto atual da recente aprovação da Resolução CNS no 10/2016, normativa regulatória para as Ciências Humanas e Sociais (CHS). Para isso, construiu-se um argumento que aborda a questão da regulação e destaca também aspectos da reflexão ética no ofício de pesquisar e na formação de pesquisadores. A metodologia combinou a análise documental e o levantamento de opiniões de pesquisadores líderes e vice-líderes de grupos de pesquisa em educação da Região Sul através do uso de um questionário web. Os resultados da pesquisa mostram que no grupo dos 53 respondentes predomina o inconformismo com a situação atual da regulação da ética em pesquisa e prevalece a ideia de que esse tema corresponde tanto à regulação como à formação. Em relação aos riscos da pesquisa em educação, as opiniões divergem e é escasso o reconhecimento de dilemas éticos nessa atividade.
\end{abstract}

Palavras-chave: Ética. Pesquisa/formação. Regulação. Ciências Humanas e Sociais. Educação.

\begin{abstract}
This article presents a research that seeks to contribute to the debates on ethics and research in the context of the recent approval of Resolution CNS No. 510/2016, specific regulatory regulation for the Human and Social Sciences (CHS). With this aim, we construct an argument that addresses the issue of regulation and also highlights aspects of ethical reflection in the research and training of researchers. The methodological strategy combined the documentary analysis and the survey of the opinions of leading researchers and vice-leaders of research groups in education of the South Region (registered in CNPq) through the use of a web questionnaire. The results of the research show that in the group of 53 respondents, the predominance of nonconformity with the current situation of the regulation of research ethics prevails and the idea prevails that this theme corresponds to both regulation and training. Regarding the risks of education research, opinions diverge and there is little recognition of ethical dilemmas in this activity.

Keywords: Ethics. Research training. Regulation. Human and Social Sciences. Education.
\end{abstract}

\section{RESUMEN}

Este artículo presenta una investigación exploratoria que busca contribuir con los debates sobre ética e investigación en el contexto actual de aprobación reciente de una normativa regulatoria para las Ciencias Humanas e Sociales (CHS) en Brasil. Para eso, construimos un argumento que aborda el tema de la regulación y también destaca aspectos de la reflexión ética en el oficio de investigar y de formar investigadores. La metodología combinó el análisis documental y el uso de una encuesta utilizando un cuestionario web para recolectar opiniones de investigadores que lideran grupos de investigación en educación de la Región Sur. Los resultados, correspondientes a las respuestas de 53 cientistas, muestran inconformismo con la situación actual de regulación de la ética en la investigación y el predominio de la idea de que el tema de ética en la investigación corresponde a dos ámbitos: el de la regulación y el de la formación. Las opiniones divergen en relación a la cuestión de los riesgos que puede generar la investigación en educación y es escaso el reconocimiento de dilemas éticos en esa actividad.

Palabras clave: Ética. Investigación/formación. Regulación. Ciencias Humanas y Sociales. Educación.

\footnotetext{
* Professora do Programa de Pós-graduação em Educação da Escola de Humanidades da PUCRS. E-mail: <monica.fare@pucrs.br>.

***esquisadora 1A CNPq. E-mail: <isacrismoura@gmail.com>.

*** Professor do Programa de Pós-graduação em Educação da Escola de Humanidades da PUCRS. E-mail: <marcos.villela@pucrs.br>.
} 


\section{ÉTICA E PESQUISA EM EDUCAÇÃo No CONTEXTO REGULATÓRIO ATUAL: A CONSTRUÇÃO DE UM ARGUMENTO}

O tema da ética na atividade científica e as questões jurídicas referidas a sua regulação preocupam os pesquisadores e estão cada vez mais presentes nas agendas de temas de investigação nacionais e internacionais. Os avanços científicos e tecnológicos e seus polêmicos desenvolvimentos têm provocado nas últimas décadas uma maior visibilidade das discussões e reflexões que relacionam ciência e ética, uma acumulação de produções e espaços acadêmicos dedicados a esses temas, assim como a institucionalização de regulações específicas.

No âmbito internacional, a Unesco, organismo das Nações Unidas especializado em Ciências Humanas e Sociais, criou em 1998 um programa dedicado a fomentar a análise da ciência e a tecnologia em um marco ético a partir de três eixos: a ética da ciência, baseado na articulação dos valores básicos e na regulação da atividade científica e suas aplicações, advertindo sobre o risco produzido pelos conflitos de interesses vinculados à pressão por publicar, à comercialização e às limitações por motivos de segurança; a ética ambiental, focada em valores morais referidos às relações com o meio ambiente, incluindo temas como câmbio climático; as pressões sobre recursos escassos e ecossistemas vulneráveis e questões éticas referidas aos novos desafios da tecnologia, com particular ênfase nas necessidades de desenvolvimento tecnológico dos países em vias de desenvolvimento e incluindo áreas como a tecnologia espacial, a nanotecnologia e a crescente capacidade tecnológica de vigiar e controlar as pessoas e a circulação da informação (UNESCO, 2008).

Ademais, esse organismo internacional reconhece que a ética ainda necessita arraigar-se na reflexão filosófica, basear-se nos direitos humanos e funcionar nos contextos científicos, porém mantendo distância crítica e independente em relação a estes (UNESCO, 2008, p. 1-2)․․

O Brasil apresenta um importante acúmulo de produções e espaços de pesquisa no campo da ética, cujos fundamentos são trabalhados principalmente pelas distintas tradições das Ciências Humanas e Sociais. Também nos últimos anos têm-se desenvolvido âmbitos e estudos da denominada ética aplicada, associados à questão ambiental, tecnológica, etc. $\mathrm{O}$ campo da Bioética, vinculado inicialmente à pesquisa médica de caráter clínico e experimental, integra-se nesse cenário amplo e diverso de grupos de pesquisa e produções que analisam os atravessamentos entre ciência e ética. Assim, na produção acadêmica nacional, é possível reconhecer

\footnotetext{
Essa tradução do espanhol ao português e todas as seguintes foram realizadas pelos autores.
}

uma pluralidade de temas, perspectivas, enfoques e abordagens provenientes principalmente da produção acadêmica.

Essa situação contrasta com o processo de institucionalização da normativa regulatória sobre ética em pesquisa, deflagrado em 1996 com a implementação de um dispositivo nacional suprarregulador que estendeu a todas as áreas de conhecimento um controle inicialmente concebido para pesquisas em saúde de caráter clínico e experimental, a partir de normativas do Conselho Nacional de Saúde (CNS). Nesse contexto, a Resolução CNS no 196/96 criou uma Comissão Nacional de Ética em pesquisa (CONEP), destinada a "implementar as normas e diretrizes regulamentadoras de pesquisas envolvendo seres humanos", aprovadas pelo Conselho mencionado, atuando nos Comitês de Ética em Pesquisa (CEP) e nas instituições envolvidas com essas atividades (BRASIL, 1996).

Esse dispositivo, denominado sistema CEP/Conep, fundamenta a regulação da ética na pesquisa para todas as áreas do conhecimento nos princípios de uma bioética fortemente influenciada pela denominada teoria principialista, originada nos Estados Unidos e ancorada em princípios usados como ferramentas de regulação moral para resolver conflitos da área médica ${ }^{2}$. Trata-se de uma perspectiva ainda hegemônica em países nos quais a bioética apresenta um desenvolvimento mais tardio, como é o caso do Brasil (DINIZ; GUILHEM, 2002)3. Também os avanços da institucionalização desse sistema parece tender à naturalização dos CEPs como espaços reguladores da ética em pesquisa nas instituições, modelo que tem sido questionado em vários países ${ }^{4}$.

Essa situação regulatória provocou nos pesquisadores das CHS diferentes reações. Inicialmente, alguns tenderam a não considerar a dita regulamentação e se mantiveram distantes dos controles dos CEPs. Também, aqueles que, por decisão própria ou por pressão institucional, submeteram suas pesquisas a esse sistema e se depararam muitas vezes com avaliações que evidenciaram uma escassa compreensão das CHS e que

\footnotetext{
2 A filiação a esses princípios consta na Resolução CNS no 96/1996: "Esta Resolução incorpora sob a ótica do indivíduo e das coletividades, referenciais da bioética, tais como, autonomia, não maleficência, beneficência, justiça e equidade, dentre outros, e visa a assegurar os direitos e deveres que dizem respeito aos participantes da pesquisa, à comunidade científica e ao Estado". A Resolução CNS no 466/12 repete a mesma ideia.

3 No entanto, a Bioética não pode ser reduzida a essa perspectiva, e sua recente constituição como campo de conhecimentos evidencia diferentes linhas de pensamento. A esse respeito se sugere consultar o trabalho de Diniz e Guilhem (2002). Também uma sintética revisão sobre esse tema em relação à pesquisa em educação pode ser consultada em De la Fare e Carvalho (2017).

${ }^{4}$ Um trabalho da antropóloga Claudia Fonseca aborda essa questão, oferece um interessante panorama das discussões internacionais sobre esse modelo e apresenta outras possibilidades de espaços de debate e regulação sobre o tema de ciência e ética (FONSECA, 2016).
} 
dificultaram a atividade científica dessas áreas. Com os avanços do funcionamento desse dispositivo regulador, as associações profissionais dessas áreas realizaram pronunciamentos formais em diversos âmbitos, demandaram a criação de uma instância específica referida à regulação da ética em pesquisa fora do Ministério da Saúde e avançaram na produção de conhecimento sobre esse tema, com um acúmulo importante de publicações que questionam a legitimidade dessa regulação ${ }^{5}$.

Ante o aumento dos conflitos com associações profissionais e pesquisadores das CHS, assim como das dificuldades associadas às avaliações das pesquisas dessas áreas no âmbito dos CEPs, uma segunda normativa (Resolução CNS no 466/12) incluiu um artigo dedicado às CHS: "As especificidades éticas das pesquisas nas ciências sociais e humanas e de outras que se utilizam de metodologias próprias dessas áreas serão contempladas em resolução complementar, dadas suas particularidades" (BRASIL, 2012, p. 11). Para isso, em 2013, foi criado na Conep um grupo de trabalho com representantes de 17 associações profissionais das CHS (GT-CHS), do qual também participou a Associação Nacional de Pós-Graduação e Pesquisa em Educação (ANPED) (MAINARDES, 2014). O GT-CHS trabalhou durante mais de um ano na elaboração de um projeto de resolução complementar, e sua aprovação aconteceu no marco de um conflito sem precedentes ${ }^{6}$. Posteriormente, essa normativa específica foi submetida à consulta pública e aprovada em 7 de abril de 2016 como Resolução CNS no 510 . No entanto, está indicada nesse documento a elaboração de outra resolução que deve tipificar os riscos das pesquisas em CHS e estabelecer um protocolo específico para essas áreas. Ou seja, a disputa pelo controle normativo da ética em pesquisa ainda permanece em aberto.

Sintetizando, a implantação verticalizada de um sistema regulador compulsório gerou um embate entre os defensores de uma ética em pesquisa regulada pelos princípios morais provenientes da bioética hegemônica, dedicada a pensar as relações pesquisadores/seres humanos participantes de pesquisas clínicas/experimentais e a tradição pluralista das CHS, associada à história e à constituição diversa dos campos de conhecimento que as compõem. Ambos os pontos de vista coincidem na defesa indeclinável da dignidade humana na pesquisa científica, porém, enquanto a Conep sustenta a universalidade dos princípios da bioética principialista como doutrina aplicável a todas

\footnotetext{
5 Um estado do conhecimento sobre esse tema pode ser consultado em: De la Fare, Machado e Carvalho (2014) e uma atualização posterior em De la Fare, Amaral e Carvalho (2017).

${ }^{6}$ Uma análise desses conflitos pode ser consultada no dossiê da Revista Brasileira de Sociologia, que conta com vários artigos de autoria de representantes do GT-CHS, entre outros: Duarte (2015), Sarti (2015), Edler (2015), Santos, Jeolás (2015), Sobtkka (2015) e Zaluar (2015).
}

as ciências, ${ }^{7}$ pesquisadores e associações profissionais das CHS questionam essa posição, propõem um âmbito governamental mais adequado para regular as relações entre ciência e ética, e defendem o uso de regulações que contemplem possibilidades reflexivas para problematizar os atravessamentos entre ciência e ética. Esses questionamentos encontram-se alinhados com as orientações da Unesco já mencionadas, que postulam o enraizamento da ética na reflexão filosófica, na defesa dos direitos humanos e seu funcionamento nos espaços científicos, porém com certo grau de autonomia.

A partir dessa análise, conjectura-se que o que está em jogo nessas lutas é o poder de definir, através da via legal, o que é ética e o que é ciência. Para as teorizações das CHS, o reconhecimento das disputas pelo monopólio da autoridade científica na ciência não constituem uma novidade.

\begin{abstract}
A sociologia da ciência repousa no postulado de que a verdade do produto - mesmo em se tratando desse produto particular que é a verdade científica reside numa espécie particular de condições sociais de produção; isto é, mais precisamente, num estado determinado da estrutura e do funcionamento do campo científico. O universo 'puro' da mais 'pura' ciência é um campo social como outro qualquer, com suas relações de força e monopólios, suas lutas e estratégias, seus interesses e lucros, mas onde todas essas invariantes revestem formas específicas (BOURDIEU, 1976, p. 1-2).
\end{abstract}

Essa teorização e outras posteriores orientam a problematização do espaço social da ciência como resultado das relações entre posições, também produto das lutas anteriores pelo monopólio da autoridade científica, entendendo que, no campo científico, poder social e competência técnica são indissociáveis (BOURDIEU, 1976; 2003a; 2003b). Nesse sentido, as disputas entre os grandes campos do conhecimento, nesse caso as CHS e as ciências médicas, antecedem ao sistema CEP/Conep. No cenário dos CEPs e da legalidade normativa, esse sistema atualizou antigos conflitos epistemológicos. E, como se sabe, "os conflitos epistemológicos são sempre, inseparavelmente, conflitos políticos, assim, uma pesquisa sobre o poder no campo científico poderia perfeitamente incluir somente questões

\footnotetext{
"Ao assumir que a Resolução GT-CHS tem caráter independente, passa-se a admitir equivocadamente que a ética em pesquisa com seres humanos, em sua essência, tem valores e pesos diferentes, dependendo da metodologia empregada. Não é este o entendimento do Colegiado da Conep. A ética em pesquisa envolvendo seres humanos é, de certo, pluralista, mutável, podendo ser analisada de diversas maneiras, por diferentes focos e ângulos e através de variadas linhas filosóficas. Mas o seu interesse é único: o respeito à dignidade do ser humano participante da pesquisa. É nisto que se fundamenta a Resolução CNS no 466/12 e que não pode se renegar por outra resolução" (BRASIL, 2014, p. 2 - grifos do autor).
} 
de índole epistemológica" (BOURDIEU, 1976, p. 78). O que Bourdieu não inclui em sua análise e que constitui um aspecto original dos conflitos na ciência brasileira é que foi através de uma suposta legalidade referida à ética na pesquisa que se intensificaram essas disputas. Um claro exemplo dessa situação é que, ante as frequentes dificuldades protagonizadas pelas avaliações dos CEPs, a Resolução CNS no 510 incluiu um artigo que esclarece que a avaliação científica dos projetos é competência das "instâncias acadêmicas específicas, tais como comissões acadêmicas de pesquisa, bancas de pós-graduação, instituições de fomento à pesquisa, dentre outros. Não cabe ao Sistema CEP/CONEP a análise do desenho metodológico em si". é competência das instâncias acadêmicas específicas (BRASIL, 2016, p. 8).

A análise desse contexto levou a se pensar que o tema da ética em pesquisa exige um olhar atento, que permita enriquecer as discussões sobre regulação, porém que também potencialize reflexões e estudos que não se limitem a essa dimensão. Nesse sentido, entende-se que a pesquisa em educação ainda necessita amadurecer as discussões sobre esse tema, ainda emergente. Um caminho possível é a problematização da indissociabilidade do binômio pesquisa/formação na abordagem dos temas da ética na pesquisa (DE LA FARE; CARVALHO, 2017), pois a relativa autonomia de um campo científico pode manifestar-se na refração ou na retradução das intervenções externas (BOURDIEU, 2003a).

De fato, no contexto de países nos quais a atividade científica se realiza principalmente em instituições de educação superior, os centros, núcleos, laboratórios, observatórios e outros espaços universitários onde a ciência se materializa encontram-se atravessados e constituídos por relações de formação, no marco dos pilares ensino/pesquisa/extensão, que sustentam a base das instituições universitárias. As salas de aula, os grupos de pesquisa ou os espaços de orientação para a formação de estudantes da graduação em iniciação à pesquisa ou de formação de pesquisadores na pós-graduação strictu sensu representam uma clara evidência dessa situação.

Em 2016, realizou-se uma pesquisa na qual se buscou contribuir com os debates atuais sobre ética na pesquisa, a partir do contexto de emergência da Resolução CNS no $510 / 2016^{8}$. Para isso, usou-se a análise documental, focalizada nas normativas do CNS e realizou-se um levantamento de opiniões de pesquisadores em educação da Região Sul, partindo-se das discussões sobre regulação, porém ultrapassando esse limite. Incluíram-se

\footnotetext{
8 A equipe de pesquisa também esteve integrada por Jonathan Henriques do Amaral, na época bolsista PNPD do Programa de Pós-graduação em Educação da PUCRS, que colaborou com a elaboração do questionário, e Julia Fernandes da Costa, bolsista de iniciação científica do Programa de Bolsas Pesquisa Alunos da PUCRS/BPA.
}

nessa consulta questões sobre regulação; relações entre pesquisa, ética e formação; identificação de riscos associados aos processos de pesquisa em educação e dilemas éticos emergentes dessa atividade. Para isso, utilizou-se um questionário $w e b$, enviado a líderes e vice-líderes de grupos de pesquisa em educação, certificados pelo Conselho Nacional de Desenvolvimento Científico e Tecnológico (CNPq) ${ }^{9}$ e localizados nos estados de Paraná, Santa Catarina e Rio Grande do Sul.

A seguir, apresentam-se neste artigo os resultados desse estudo organizados em três subseções. Na primeira, introduz-se uma breve análise da Resolução CNS no 510/16, iniciando-se pelos princípios éticos explicitados nesse documento para logo apresentar aspectos procedimentais referidos ao controle burocrático dos projetos de pesquisa. Na segunda subseção, introduzem-se decisões metodológicas envolvidas no uso do questionário web e análises dos dados provenientes das informações e opiniões dos questionários, referidas principalmente à dimensão regulatória da ética em pesquisa. Dedica-se a última subseção a discutir o tema dos contrastes entre regulação e formação em ética em pesquisa e a introduzir a discussão sobre dilemas éticos envolvidos no oficio de pesquisar. Também usou-se para isso informações levantadas através do questionário mencionado. Pensou-se que esse pode ser um caminho fértil para aprofundar os debates sobre os atravessamentos entre ciência e ética no campo da pesquisa em educação e nas CHS em geral.

\section{CONCEPÇÃO DA ÉTICA, PRINCÍPIOS E PROCEDIMENTOS DA RESOLUÇÃO CNS № 510/16}

Uma das questões a serem destacadas da Resolução CNS no 510/16 é a concepção de ética que apresenta e os princípios que a sustentam. A diferença das resoluções anteriores do CNS, nas que não se identifica uma definição sobre ética (mesmo incluindo um capítulo sobre termos e definições), esse documento especifica que a ética é uma construção humana e, portanto, histórica, social e cultural (BRASIL, 2016, p. 1). No segundo capítulo se estabelecem 11 princípios éticos, que constituem a base dos procedimentos estabelecidos posteriormente e que, como se mostra a seguir, resultam mais abrangentes que os da bioética principialista (autonomia, não maleficência, beneficência, justiça e equidade).

Os dois primeiros abrangem o conjunto de relações sociais que envolvem e dinamizam os processos de pesquisa. Assim, quando se menciona o "reconhecimento da liberdade e da autonomia de todos os participantes do

\footnotetext{
9 Base de dados disponível em <http://lattes.cnpq.br/web/dgp>, acesso em: 20 jan. 2017.
} 
processo de pesquisa" (BRASIL, 2016, p.5), esclarece-se que este inclui a liberdade científica e acadêmica. $\mathrm{O}$ seguinte princípio refere a "defesa dos direitos humanos e recusa do arbítrio e do autoritarismo nas relações que envolvem os processos de pesquisa" (ibid.). Destaca-se que essas dimensões aparecem pela primeira vez nas resoluções do CNS e ambas ampliam a delimitação que restringe a reflexão sobre ética e ciência exclusivamente ao vínculo entre pesquisador e sujeitos participantes na lógica da relação sujeito/objeto, predominante nas pesquisas clínicas e experimentais.

O quarto princípio alude a um aspecto inerente ao ofício de pesquisar, como é a socialização da produção de conhecimento, apresentado através da ideia da democratização de seus produtos e resultados. O que não se refere só ao âmbito científico, mas também aos grupos e populações com os quais os pesquisadores trabalham em suas diferentes abordagens, incluindo a pertinente recomendação de divulgação em um formato acessível a esses grupos e populações.

Os dois princípios seguintes abordam mais especificamente, embora não exclusivamente, a relação entre sujeitos participantes da pesquisa e pesquisadores: "Respeito aos valores culturais, sociais, morais e religiosos, bem como aos hábitos e costumes, dos participantes das pesquisas" e "recusa de todas as formas de preconceito, incentivando o respeito à diversidade, à participação de indivíduos e grupos vulneráveis e discriminados e às diferenças dos processos de pesquisa" (ibid.)

Posteriormente, introduzem-se as garantias que exige o processo de pesquisa em relação ao "assentimento ou consentimento dos participantes das pesquisas, esclarecidos sobre seu sentido e implicações"; "confidencialidade das informações, da privacidade dos participantes e da proteção de sua identidade, inclusive do uso de sua imagem e voz" e uso das informações associadas à pesquisa, que não prejudiquem os sujeitos participantes (ibid.).

Os dois últimos princípios abordam a questão do risco envolvido nos processos de investigação em CHS, a partir de uma perspectiva situada, que reconhece tanto as situações de vulnerabilidade, risco e discriminação experimentadas por muitos dos sujeitos e grupos participantes das pesquisas das CHS como o "compromisso de todos os envolvidos na pesquisa de não criar, manter ou ampliar as situações de risco ou vulnerabilidade para indivíduos e coletividades, nem acentuar o estigma, o preconceito ou a discriminação"; e também "propiciar assistência a eventuais danos materiais e imateriais, decorrentes da participação na pesquisa" (ibid.).

Retomando a ideia de que a ciência se desenvolve principalmente em espaços nos quais as relações éticas necessitam ser pensadas na indissociabilidade do binômio pesquisa/formação, entende-se que os princípios éticos da Resolução CNS no 510 apresentam um material interessante para potencializar a reflexão no amplo espectro de relações envolvidas no ofício de pesquisar. Trata-se de recuperar os sentidos dessas dimensões no fazer pesquisa/formar em pesquisa. Sem a pretensão de aprofundar questões filosóficas relativas à ética, mas de trazer à luz contribuições da filosofia da educação em relação a esse tema, é interessante recordar que "a questão do outro interpela a educação, especialmente porque as normas e princípios universais, pela sua pretensa abrangência, têm dificuldade em se deixar mesclar pelo estranho, incluir o singular e tudo aquilo que escapa às regularidades" (HERMANN, 2014, p.16). Essa interpelação também alude à pesquisa/ formação desenvolvida nas universidades, atualmente tensionada por uma regulação que tende a estandardizar procedimentos, banalizando a reflexividade envolvida na singularidade e no estranhamento produzidos nos processos de pesquisa e suas relações.

Ademais dos princípios éticos, a Resolução CNS no 510/16 introduz algumas novidades em relação aos procedimentos regulatórios do sistema CEP/Conep para as pesquisas das CHS, aborda-se nesta seção os que se considera mais destacado. Por uma parte, essa resolução estende o alcance do controle às produções que habitualmente não eram incluídas, como os trabalhos de conclusão de curso, monografias ou produções similares, para os que se indica a obrigação de apresentar o protocolo de pesquisa ao sistema CEP/Conep (BRASIL, 2016). Por outra, inclui uma tipificação de pesquisas que são excetuadas do registro e avaliação nesse sistema:

I - pesquisa de opinião pública com participantes não identificados ${ }^{10}$; II - pesquisa que utilize informações de acesso público, nos termos da Lei no 12.527 , de 18 de novembro de 2011; III - pesquisa que utilize informações de domínio público; IV - pesquisa censitária; V - pesquisa com bancos de dados, cujas informações são agregadas, sem possibilidade de identificação individual; VI - pesquisa realizada exclusivamente com textos científicos para revisão da literatura científica; VII - pesquisa que objetiva o aprofundamento teórico de situações que emergem espontânea e contingencialmente na prática profissional, desde que não revelem dados que possam identificar o sujeito; e VIII - atividade realizada com o intuito exclusivamente de educação, ensino ou treinamento sem finalidade de pesquisa científica, de alunos de graduação, de curso técnico, ou de profissionais em especialização (BRASIL, 2016, p. 1-2 - grifos do autor).

\footnotetext{
${ }^{10}$ Definida como "consulta verbal ou escrita de caráter pontual, realizada por meio de metodologia específica, através da qual o participante é convidado a expressar sua preferência, avaliação ou o sentido que atribui a temas, atuação de pessoas e organizações, ou a produtos e serviços; sem possibilidade de identificação do participante" (BRASIL, 2016, p. 3).
} 
Destaca-se a relevância que apresenta a questão da identificação dos sujeitos e das fontes de informação da pesquisa nessa nova regulação. Nessa caracterização se estabelecem como critérios para a não inclusão de pesquisas no sistema $\mathrm{CEP} / \mathrm{Conep}$ tanto a não identificação dos sujeitos em pesquisas denominadas "de opinião pública" como aquelas que envolvem uso de bancos de dados; assim como as que produzem desenvolvimentos teóricos a partir de situações vinculadas às práticas profissionais, destacando novamente a questão do anonimato. $\mathrm{Ou}$ seja, a normativa em questão fundamenta a execução do dispositivo regulador em face da ausência de identificação dos sujeitos participantes, questão que às vezes também envolve evitar a identificação nominal das instituições.

Essas exceções levam a formular uma pergunta: é o anonimato ou o uso de informações públicas que garantem que as pesquisas possam ser desenvolvidas sem as atuais interferências do sistema CEP/Conep, ou seja, como se desenvolviam antes da criação desse dispositivo de controle? Se o anonimato ou o uso de informações públicas permitem que as questões éticas sejam "controladas" pelos próprios pesquisadores, não se estaria diante de um dispositivo regulador preocupado principalmente com as consequências jurídicas que podem surgir a partir da identificação de sujeitos e instituições nas pesquisas? Evidentemente, a polêmica institucionalização do sistema $\mathrm{CEP} /$ Conep continua gerando muitas interrogações para os pesquisadores das CHS.

Outra modificação introduzida pela Resolução CNS no 510/16 e referida aos procedimentos regulatórios que merece destaque é a delimitação do alcance da avaliação dos CEPs, que atualmente não podem interferir na análise das perspectivas teórico-metodológicas dos projetos de pesquisa das CHS, questão já abordada no início deste artigo. Também se reconhecem alterações referidas à construção do processo de obtenção do consentimento ou assentimento livre e esclarecido (CAE), envolvendo "uma relação de confiança entre pesquisador e participante, continuamente aberto ao diálogo e ao questionamento, podendo ser obtido ou registrado em qualquer das fases de execução da pesquisa..." (BRASIL, 2016, p.5). Assim, a obtenção do CAE deixa de ser engessada pela exigência do uso do documento Termo de Consentimento Livre e Esclarecido (TCLE), assinado pelos participantes das pesquisas antes de se iniciar qualquer trabalho empírico que envolva "seres humanos", como consta nas Resoluções do CNS anteriores. Ademais, a comunicação que se espera que se estabeleça nesse processo abre outras possibilidades. Dessa forma o CAE pode ser obtido por "expressão oral, escrita, língua de sinais ou outras formas que se considerem adequadas" às características dos participantes e às metodologias das pesquisas das CHS e "deve ocorrer de maneira espontânea, clara e objetiva, e evitar modalidades excessivamente formais, num clima de mútua confiança, assegurando uma comunicação plena e interativa" (BRASIL, 2016, p. 5).

Também ressalta-se que essa normativa inclui, em suas disposições transitórias, a estimulação do ingresso dos pesquisadores das CHS na composição dos CEPs existentes, assim como a criação de novos, que mantenham o caráter interdisciplinar de sua composição (BRASIL, 2016).

Por último, esclarece-se que, nessa subseção, mais do que esgotar a análise da Resolução CNS no 510/16, documento extenso e caracterizado pelo predomínio de excessivas prescrições regulatórias, limita-se esta análise ao resgate dos pontos considerados relevantes para introduzir os dados provenientes das respostas dos pesquisadores que são analisadas e discutidas nas próximas subseções.

\section{REGULAÇÃo DA ÉTICA NA PESQUISA: AS VOZES DOS PESQUISADORES EM EDUCAÇÃo da REGIÃo SUL}

Antes de se iniciar a apresentação e análises dos dados coletados através do questionário web, considera-se oportuno introduzir esclarecimentos sobre a metodologia de trabalho utilizada nessa etapa do estudo e sobre as escolhas realizadas pela equipe de pesquisa. A ideia inicial foi efetuar um levantamento das opiniões de pesquisadores da área Educação ${ }^{11}$, por isso escolheu-se como fonte de informações o Diretório de Grupos de Pesquisa do CNPq, que permitiu caracterizar esse universo a partir das informações públicas disponíveis e deu acesso aos endereços eletrônicos dos pesquisadores que lideram esses espaços.

As informações estatísticas do Diretório de Grupos de Pesquisa do $\mathrm{CNPq}$ apresentam um interessante panorama do crescimento dos grupos de pesquisa em Educação no Brasil. Embora se trate de uma característica de todas as áreas de conhecimento, nesse caso o crescimento é expressivo, sendo que a quantidade de grupos dessa área passou de 201 (3,1\% do total), em 1993, momento de criação dessa base de dados, a 3.595 (9,6\% do total) em 2016. Nesse ano, Educação foi a área que concentrou a maior porcentagem de grupos de pesquisa, seguida do Direito (1.386 grupos, 3,7\% do total), Administração (1.311 grupos, 3,5\% do total) e Agronomia (1.254 grupos, $3,3 \%$ do total).

Em outubro de 2016, momento de realização deste estudo, selecionaram-se desse diretório os grupos de

\footnotetext{
${ }^{11}$ Menciona-se como antecedente a consulta sobre este tema organizada pelo Fórum de Coordenadores de Programas de Pós-Graduação em Educação (FORPRED), cujos resultados podem ser consultados no trabalho de Carvalho e Machado (2014).
} 
pesquisa em Educação da Região Sul certificados, atualizados e com ao menos um pesquisador com título de doutor. Foram enviados 472 questionários para líderes de pesquisa da Região Sul (197 para os de Rio Grande do Sul, 109 para os de Santa Catarina e 166 para os de Paraná) e 263 para os vice-líderes (114, 65 e 84 respectivamente). Ao enviar os questionários, 45 retornaram porque os endereços eletrônicos não estavam atualizados. Finalmente, o questionário contou com 734 destinatários. Desse total, recebeu-se o retorno de 53 pesquisadores (7,2\% do total). Desse total, $39,6 \%$ das respostas corresponderam tanto aos pesquisadores do Paraná como do Rio Grande do Sul e 20,8\% aos de Santa Catarina.

Sabia-se, e ainda se está ciente, dos limites de um levantamento de informações e opiniões através do uso dessa metodologia, porém optou-se por utilizá-la aproveitando algumas de suas vantagens (possibilidade de acessar um número relevante de pesquisadores da Região Sul e baixo custo). Como estratégia, buscando obter uma maior quantidade de respostas, elaborou-se um questionário breve e decidiu-se incluir líderes e vice-líderes desses grupos, porém, em que pesem esses esforços, o baixo nível de resposta ao questionário resultou em um dado de difícil interpretação. Isso pode ser associado tanto à técnica usada como ao escasso tempo disponível pelos pesquisadores para responder, com cotidianos dominados pelo excesso de atividades acadêmicas, assim como devido ao escasso interesse ou rejeição pelo tema.

O questionário utilizado incluiu um total de 11 questões. Sete delas fechadas, referidas a informações dos grupos de pesquisa (estado no qual se localiza, ano de criação, espaços de formação sobre regulação da ética na pesquisa dos próprios grupos) e dos pesquisadores (distribuição por faixa etária; nível de formação; a áreas, âmbitos e anos de atuação na Educação Superior; a espaços de formação sobre regulação da ética na pesquisa nas instituições nas que desenvolvem atividades); à submissão de projetos ao sistema CEP/Conep, considerando também o uso da Plataforma Brasil ${ }^{12}$ e a vinculação do tema da ética na pesquisa sobre formação, regulação ou sobre essas duas dimensões. Outras quatro questões eram abertas, referidas a opiniões sobre a Resolução CNS $\mathrm{n}$ - 510/16 e sua adequação às especificidades das CHS, incluindo uma pergunta sobre o tema dos riscos e uma última questão dedicada a levantar opiniões sobre dilemas éticos no ofício de pesquisar.

Dos líderes e vice-líderes que responderam ao questionário, a maioria (46 pesquisadores, 86,8\%)

\footnotetext{
${ }^{12}$ Página web criada pela Conep para o registro de projetos que serão avaliados pelos CEPs. Disponível em: <http://www.saude.gov.br/ plataformabrasil>, acesso em: 10 mar. 2016
}

encontra-se na faixa etária de mais de $40 \operatorname{anos}^{13}$ e os sete restantes $(13,2 \%)$ possuem entre 30 e 40 anos de idade. Quase a totalidade dos respondentes são doutores e dez deles realizaram estágios de pós-doutorado (oito no exterior e dois no país), e só um se identificou como mestre. A maioria atua em cursos de pós-graduação e de graduação (46 respondentes, $86,8 \%$ ) e sete $(7,2 \%)$ o fazem exclusivamente na graduação. Analisando o tempo de atuação na Educação Superior, a maioria (35 pesquisadores, 66\%) desenvolve atividades nesses espaços há mais de dez anos e, nesse grupo, dez (18,9\% do total) o fazem há mais de 20 anos. Outro grupo de 12 pesquisadores $(22,6 \%)$ apresenta entre seis e dez anos de atuação na Educação Superior. Os seis restantes (11,3\%) têm uma inserção mais recente, de até cinco anos.

Os dados apresentados revelam que se trata de recursos humanos altamente qualificados, que, pelo tempo de atuação declarado, desenvolviam atividades na Educação Superior, no período de vigência da polêmica Resolução CNS no 466/12. Um grupo deles (18,9\%) já atuava na Educação Superior quando entrou em vigor a Resolução CNS 196/96, que institucionalizou o sistema CEP/Conep. Esse dado também se confirma quando se considera o período de funcionamento dos grupos de pesquisa que os respondentes lideram: $31(58,5 \%)$ foram criados há mais de cinco anos e, dentro desse grupo, oito ( $15,1 \%$ do total) declararam que os grupos que lideram foram criados há 15 ou mais anos. Só quatro grupos (7,5\%) têm menos de um ano de funcionamento.

Quanto à dimensão regulatória do sistema CEP/ Conep, os pesquisadores manifestaram diferentes situações em relação à submissão dos projetos de pesquisa para avaliação dos CEPs das instituições universitárias em que atuam. Um grupo de 26 pesquisadores $(49,1 \%)$ afirmou que já havia feito em mais de uma oportunidade; nove (17\%), apenas uma vez; e 18 (43\%) nunca submeteram seus projetos a esses espaços de avaliação. Esse dado indica que no plano fático o reconhecimento da legitimidade do sistema CEP/Conep é relativo. Ressalta-se que a maioria dos respondentes que encaminharam seus projetos para a avaliação dos CEPs opinaram que submeteram seus projetos a essa instância por orientação do estabelecimento em que atuam (26 respostas, 72,2\%) e só nove (25\%) o fizeram por própria convicção.

Em relação à formação no tema de regulação da ética em pesquisa, um grupo de 15 respondentes (28,3\%) declarou não ter tido nenhum espaço de formação nos níveis da Educação Superior em que atua. No entanto, 25 líderes $(47,2 \%)$ afirmaram que foram e são disponibilizados esses espaços na graduação e na pós-

\footnotetext{
${ }^{13}$ Entre estes, 27 pesquisadores (50,9\%) possuem entre 41 e 50 anos de idade, $10(18,9 \%)$ possuem entre 51 e 60 anos de idade e nove (17\%) possuem mais de 60 anos de idade.
} 
graduação, um $(1,9 \%)$ recebeu formação sobre esse tema só na graduação e $12(22,6 \%)$, exclusivamente na pós-graduação. Em relação aos grupos de pesquisa que lideram, 40 pesquisadores $(75,5 \%)$ responderam que disponibilizaram espaços formativos sobre o tema e 13 $(24,5 \%)$ que não o fizeram.

Essas opiniões refletem a escassa legitimidade de um sistema avaliador baseado em um dispositivo compulsório que, paradoxalmente, dista do desejável em relação às exigências da reflexividade inerente tanto à ética como ao ofício de pesquisar. Regulações da ética na pesquisa existem em diferentes países, porém a naturalização do sistema CEP/Conep resulta, como mínimo, discutível. Quanto às atividades de formação sobre os usos dessa regulação, as opiniões identificam espaços institucionais que assumiram essa tarefa, destacando principalmente os grupos de pesquisa que os respondentes lideram como âmbitos em que esses temas foram trabalhados.

Os aspectos operacionais da avaliação dos projetos de pesquisa, que deve ser realizada através do uso da denominada Plataforma Brasil, também dividiram as opiniões dos pesquisadores, porém predomina a consideração dessa plataforma como pouco amigável. Dos líderes e vice-líderes que já submeteram seus projetos à análise do CEP, 14 (40\%) opinaram que o preenchimento de dados é rápido, mas consideram a plataforma pouco amigável; $12(34,3 \%)$ avaliaram o preenchimento de dados demorado e tampouco consideram a plataforma amigável; cinco $(14,3 \%)$ julgaram o preenchimento de dados demorado e consideram a plataforma amigável; e um grupo pequeno (quatro respondentes, 11,4\%) afirmou que o preenchimento de dados é rápido e a plataforma amigável.

Em relação à adequação da Resolução CNS no $510 / 2016$ às especificidades das CHS, as respostas também se apresentaram divididas e delas surgem interessantes questionamentos. Um conjunto de 17 respondentes (32\%) posicionou-se como favorável a essa normativa (pois "contempla vários tipos de pesquisa"; "estão bem especificados os direitos, além de a concepção teórica ser histórico e social" e "servem para orientar o pesquisador"). Uma proporção similar (16 pesquisadores, $30,2 \%$ ) posicionou-se como desfavorável, pois, "não contempla a diversidade metodológica da área"; "porque há muitas especificidades da área que são muito diferentes da área da saúde e ciências naturais [base da resolução]"; e "porque parte de outro campo de conhecimento com exigências bem distintas". Um grupo menor, dez pesquisadores $(18,9 \%)$ concordou parcialmente (pois "não conseguiu libertar-se do modelo biomédico e da área da saúde"; "houve alguma flexibilização, mas os critérios ainda têm muitos pontos de contato com pesquisas na área da saúde"); e o mesmo número de pesquisadores afirmaram desconhecer a Resolução no 510/2016 e, portanto, manifestaram que não tinham condições de opinar.

Como já foi apresentado na primeira parte deste artigo, os riscos envolvidos nas atividades de pesquisa nas CHS constituem uma questão em aberto para a regulação normativa da ética na pesquisa. Esse tema não é novo no campo das CHS, pois verifica uma vasta produção, tanto como centro da teoria social a partir das contribuições de vários autores (entre outros, Anthony Giddens e Ulrick Beck) como a partir de uma delimitação mais restrita, sem deixar de reconhecer o decisivo peso cultural e social que esse conceito envolve (GUIVANT, 1998). Ou seja, novamente a normativa sobre ética em pesquisa parece querer introduzir, na gradação dos riscos previstos para uma próxima resolução, uma única interpretação de um conceito amplamente abordado por diferentes perspectivas no contexto da pluralidade teórica e metodológica das CHS.

Ao responder sobre a classificação de tipos de riscos das pesquisas propostos pela Resolução no 510/2016, 13 pesquisadores $(24,5 \%)$ opinaram que é adequada (pois "respeita as especificidades dos pesquisados e oferece livre arbítrio"); 17 (32\%) enfatizaram sua inadequação ("como a normativa para riscos ainda não foi publicada pela Conep [está em elaboração], a 510 ainda trabalha com o pressuposto inadequado para as CHS de que toda pesquisa envolve riscos"); seis (11,3\%) pensam que a classificação é parcialmente adequada ("deve ser um norte/referência", "ainda precisa ser aprimorada" e "em Ciências Humanas e Sociais é muito relativo classificar os riscos"); e outros 14 (26,4\%) líderes e vice-líderes afirmaram desconhecer a resolução ou a classificação de riscos.

Alguns dos líderes e vice-líderes discordaram sobre a classificação de riscos que a Resolução no 510/2016 propõe. Então, ante a pergunta do questionário - "Você acredita que a pesquisa em Ciências Humanas e Sociais acarreta algum tipo de risco para seus participantes? Em caso positivo, qual(is)?" -, $20(37,7 \%)$ responderam que as pesquisas dessa área do conhecimento não causam risco algum aos participantes; 14 (26,4\%) pensam que depende da pesquisa e da maneira como ela é aplicada (com questionários, visitação, acompanhamento de atividades, local do campo de pesquisa); e 19 (35,8\%) pensam que as pesquisas dessa área do conhecimento podem causar riscos ("riscos de danos morais, em caso de identificação dos sujeitos e de falta de respeito do pesquisador em relação aos sujeitos" e "quando uma pesquisa não tem um compromisso com a "neutralidade científica' pode gerar um conhecimento ideológico que não corresponde à realidade dos fatos").

Embora as opiniões apareçam divididas, as principais tendências das opiniões dos pesquisadores que 
responderam ao questionário demonstram inconformismo com a situação atual da regulação da ética em pesquisa. Resulta evidente que, nos casos em que os participantes deste estudo encaminharam seus projetos para avaliação do sistema $\mathrm{CEP} / \mathrm{Conep}$, fizeram-no majoritariamente pelas pressões institucionais associadas a esse modelo regulatório. E mesmo com as modificações introduzidas pela Resolução CNS no 510/16, uma boa parte questiona ou ainda desconhece essa normativa.

A questão dos riscos das pesquisas em educação é um tema polêmico, e as opiniões aparecem divididas, com uma porcentagem significativa de respostas que negam a existência de algum tipo de risco e uma proporção similar que identifica riscos "simbólicos" em relação aos efeitos das pesquisas nos participantes. Um terceiro grupo, menos expressivo quantitativamente, avalia a necessidade de uma análise situada dos riscos nas singularidades de cada pesquisa. Conjectura-se que a situação em aberto de uma nova norma que estabeleça uma tipificação específica para as CHS e crie um novo protocolo para essas áreas será arena de novas disputas e conflitos, porém os dados apresentados evidenciam que o conceito de risco em relação à ética na pesquisa em educação exige debate dos próprios espaços de pesquisa, no marco de uma relativa autonomia que permita construir posições adequadas às realidades com as quais os pesquisadores trabalham cotidianamente.

\section{Pesquisa em EduCAÇÃo, FORMAÇÃo E DILEMAS ÉTICOS}

A formação de um pesquisador na pós-graduação stricto sensu é resultado da convergência de um amplo conjunto de relações e espaços formais: as disciplinas dedicadas à pesquisa e aquelas que abordam especificidades temáticas e teórico-metodológicas trabalhadas nas produções; as atividades dos grupos de pesquisa; as trocas entre pares, estudantes envolvidos em processos de formação; as palestras e os eventos acadêmicos sobre os temas trabalhados; as bancas de qualificação e de defesa final; as relações de orientação. Junto com isso muitos outros espaços informais não deixam de representar momentos significativos para essa formação.

Nesse amplo leque de atividades interessa aqui resgatar para problematizar, nas relações entre ciência, ética e formação em pesquisa, a ideia de transmissão de um oficio. "Boa parte do ofício de cientista é adquirido por meio de modos de transmissão que são inteiramente práticos" (BOURDIEU, 2005, p. 311), que envolvem hábitos científicos, conceito que alude a um modus operandi científico que funciona em um estado prático de acordo com normas da ciência, porém sem considerar essas normas como seu princípio explícito...” (p. 312).
Muitas vezes, a transmissão desse oficio "acontece na privacidade do 'laboratório' ou, para falar mais modestamente, na oficina - no sentido da oficina do artesão..." (BOURDIEU, 2005, p. 308). Essas ideias colaboram para reposicionar a discussão sobre pesquisa, pois permitem contemplar a reflexão ética no marco de relações situadas no exercício e nas singularidades dos processos de pesquisa/formação.

Retomando as respostas dos pesquisadores, para uma grande parte dos respondentes $(37,69,8 \%)$ a pesquisa em Educação se relaciona com a regulação e com a formação; para outros cinco $(9,4 \%)$, vincula-se exclusivamente à formação; alguns deles esclareceram que tem a ver "com a convicção de sujeito e de mundo do pesquisador" e "com o caráter das pesquisas e as instâncias que envolvem". Outros nove (17\%) optaram por vincular a ética exclusivamente à regulação.

Se dispositivos reguladores alheios ao ofício de pesquisar e de seus atravessamentos com a ética impõem a obediência às normas através do preenchimento de formulários, está se falando mais de espaços de controle legal que de movimentos reflexivos que permitam problematizar as relações entre ética e ciência. No entanto, a questão tampouco é fechar a reflexão ética aos pequenos espaços de orientação, grupos de pesquisa ou disciplinas nem propor a eliminação de qualquer instância regulatória mais ampla. Trata-se principalmente de resgatar essa dimensão que parece ter sido sequestrada por uma burocracia ancorada na legalidade. Pensar esse movimento implica também repensar o modelo CEP nos âmbitos das instituições universitárias e tentar ensaiar outras formas de discutir e avaliar coletivamente os aspectos éticos das pesquisas.

Um tema relevante e que incluiu-se como última resposta do questionário foi o referido aos dilemas éticos que as pesquisas em educação podem gerar. Para tal, indagou-se se os pesquisadores respondentes já haviam enfrentado algum dilema ético nessa atividade. A maioria dos respondentes afirmou que não (41 pesquisadores, $77,4 \%$ ). Em contraste, uma minoria (12 pesquisadores, $22,6 \%)$ respondeu afirmativamente, e ante a solicitação de exemplos nos casos das respostas afirmativas surgiram interessantes informações referidas a diversos aspectos: "pedir autorização para observar pessoas em um parque público"; "durante a observância de pacientes em estágio terminal de vida como fonte de pesquisa"; "repensar e reavaliar o equilíbrio entre a liberdade do participante e a insistência da equipe de pesquisadores para a obtenção de respostas a questionários"; "plágio de alunos em mestrado, encomenda para terceiros de sua pesquisa"; "quando a pesquisa envolveu o uso de drogas pelos funcionários da instituição e houve proibição na apresentação dos resultados"; "acompanhei uma 
pesquisa em que as opiniões dadas pelos professores faziam uma grande crítica à atuação preconceituosa do diretor [..], houve a preocupação da pesquisadora com a associação das pessoas às críticas, na medida em que se tratava de uma pesquisa-ação em uma unidade escolar em relação à qual os participantes teriam, na sequência, acesso à publicação". Outros pesquisadores relataram exemplos de problemas com o sigilo das entrevistas e com a pesquisa no próprio ambiente de trabalho. Uma opinião mais abrangente expressou que os dilemas éticos, também considerados políticos e estéticos, são próprios da vida e se apresentam nas atividades de pesquisa e de docência. Um pesquisador reconheceu como dilema ético "permanecer ou não permanecer no comitê de ética".

Esse conjunto de respostas e as singularidades apresentadas brevemente em cada situação exemplificam situações cotidianas que envolvem escolhas diante de relações entre ética e pesquisa no cotidiano do pesquisador. Sem pretender aprofundar a discussão filosófica sobre esse tema, questão que precisa ser aprofundada em um trabalho próximo, entende-se que o oficio de pesquisar envolve diversos encaminhamentos nesse "jogo de escolhas condicionadas" que é a pesquisa, incluindo decisões que demandam problematizações teóricas, epistemológicas, metodológicas, políticas e reflexões éticas. Em especial, nesse último aspecto, referido à tensão produzida entre princípios e normas de pretendida universalidade e singularidade de cada pesquisa, que opera em uma dinâmica de relações com outros em diferentes espaços.

\section{CONSIDERAÇÕES FINAIS}

Como apresentado neste artigo, o tema da regulação da ética na pesquisa na ciência brasileira continua em disputa, especialmente perante a tarefa de elaborar e aprovar uma nova normativa que complete aspectos importantes da regulação burocrática das pesquisas em CHS. Porém, entende-se que essas lutas necessitam estar acompanhadas por uma reflexão crítica que resgate a relativa autonomia desse campo nesse cenário, não só no sentido de institucionalizar um espaço adequado e uma regulação acorde às especificidades próprias, mas também na incorporação do conjunto de temas vinculados à reflexão ética nas práticas de pesquisa/ formação. Como já foi assinalado no corpo do trabalho, o grupo de pesquisadores respondentes se inclina pela crítica ao atual sistema CEP/Conep, mesmo incluindo uma nova resolução específica para as CHS, ou por um relativo reconhecimento de certo avanço ante as normativas anteriores, assim como pelo destaque da importância desse tema nos processos de formação em pesquisa.
Através da apresentação deste estudo exploratório intenta-se produzir um movimento de abertura a questões que afetam os pesquisadores em relação ao tema da ética em pesquisa. Em que pesem as limitações deste estudo e a impossibilidade de se ter trabalhado com uma amostragem representativa, considera-se que as opiniões e informações provenientes dos pesquisadores que lideram grupos de pesquisa reconhecidos institucionalmente constituem um material valioso e que deverá ser trabalhando em uma próxima publicação. Entende-se que a construção de uma agenda de temas sobre as relações entre ciência e ética exigirá incluir aprofundamentos sobre temas como dilemas éticos, discussões sobre os riscos envolvidos nas pesquisas em CHS ou a invenção e o resgate de outros conceitos próprios dessas áreas que problematizem o amplo conjunto de relações envolvidas nos processos de pesquisa no campo educacional.

\section{REFERÊNCIAS}

BOURDIEU, Pierre. (1976). El campo científico. In: Intelectuales, política y poder. Traducción de Alicia B. Gutiérrez. Buenos Aires: Eudeba, 2006.

Los usos sociales de la ciencia. Buenos Aires: Nueva Visión, 2003a.

El oficio de científico: Ciencia de la ciencia y reflexividad. Traducción de Joaquín Jordá. Barcelona: Anagrama, 2003b.

La práctica de la sociología reflexiva (Seminario de Paris). In: BOURDIEU, Pierre; WACQUANT, Loïc; BOURDIEU, Pierre. Una invitación a la sociología reflexiva. Buenos Aires: Siglo XXI, 2005.

BRASIL. Resolução 01/1988: regulamenta o credenciamento de Centros de Pesquisa no país e recomenda a criação de um Comitê de Ética em Pesquisa (CEP) em cada centro. Ministério da Saúde/Conselho Nacional de Saúde, Brasília, 1988.

Resolução 196/1996: diretrizes e normas regulamentadoras de pesquisas envolvendo seres humanos. Ministério da Saúde/Conselho Nacional da Saúde, Brasília, 1996.

Resolução 466/2012: diretrizes e normas regulamentadoras de pesquisas envolvendo seres humanos. Ministério da Saúde/Conselho Nacional de Saúde, Brasília, 2012.

Resolução 510/2016: ética em pesquisa em Ciências Humanas e Sociais. Ministério da Saúde/Conselho Nacional de Saúde, Brasília.

Comissão Nacional de Ética em Pesquisa. Carta da

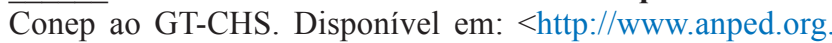
$\mathrm{br} /$ sites/default/files/resources/CONEP_Carta_sobre_Res CHS_3_frv.pdf $>$. Acesso em: 22 fev. $201 \overline{7}$.

CARVALHO, Isabel Cristina de Moura; MACHADO, Frederico Viana. A regulação da pesquisa e o campo biomédico: considerações sobre um embate epistêmico desde o campo da educação. Práxis Educativa, Ponta Grossa, v. 9, n. 1, p. 199209, jan./jun. 2014. 
DE LA FARE, Mónica; MACHADO, Frederico Viana; CARVALHO, Isabel Cristina de Moura. Breve revisão sobre regulação da ética em pesquisa: subsídios para pensar a pesquisa em educação. Práxis Educativa, Ponta Grossa, v. 9, n. 1, p. 247-283, jan./jun. 2014.

DE LA FARE, Mónica; AMARAL, Jonathan Henriques; CARVALHO, Isabel Cristina de Moura. In: BEZERRA, A. da Augusta; NASCIMENTO, Marilene Batista da Cruz (Org.). Ciência, Educação e Políticas de Formação. Sergipe: Tiradentes (no prelo).

DE LA FARE, Mónica; CARVALHO, Isabel Cristina de Moura. Ética e pesquisa em Educação: tensões entre autonomia e regulação. In: SANTOS, Luis Henrique Sacchi; KARNOPP, Lodenir Becker (Org.). Ética em pesquisa em Educação: questões e proposições. Porto Alegre: PPGEDU: UFRGS, 2017.

DINIZ, Débora; GUILHEM. O que é bioética. São Paulo: Brasilense, 2002.

DUARTE, Luis Fernando Dias. A ética em pesquisa nas Ciências Humanas e o imperialismo bioético no Brasil. Revista Brasileira de Sociologia, Brasília, v. 3, n. 5, p. 29-52, jan./jun. 2015. Disponível em: <http://www.sbsociologia.com.br/revista/ index.php/RBS/issue/view/9>. Acesso em: 20 nov. 2016.

EDLER, Flavio. A Húbris Bioética: rumo a uma polícia epistemológica? Revista Brasileira de Sociologia, Brasília, v. 3, n. 5, p. 95-113, jan./jun. 2015. Disponível em: <http://www. sbsociologia.com.br/revista/index.php/RBS/issue/view/9>. Acesso em: 20 out. 2016.

FONSECA, Claudia. Situando os comitês de ética em pesquisa: o sistema CEP (Brasil) em perspectiva. Horizontes Antropológicos, Porto Alegre, ano 21, n. 44, p. 333-369, jul./dez. 2015.

GUIVANT, Julia S. A trajetória das análises de risco: da periferia ao centro da teoria social. Revista Brasileira de Informações Bibliográficas - Anpocs, n. 46, p. 3-38, 1996.
HERMANN, Nadja. Ética e Educação: outra sensibilidade. Belo Horizonte: Autêntica, 2014.

MAINDARDES, Jefferson. Apresentação. Práxis Educativa, Ponta Grossa, v. 9, n. 1, p. 197-198, jan./jun. 2014.

SANTOS, Luis Antonio Castro; JEOLÁS, Leila. Uma Comissão Nacional de Ética na Pesquisa, as Ciências Biomédicas e as Ciências Humanas: trespassing à brasileira. Revista Brasileira de Sociologia, Brasília, v. 3, n. 5, p. 239-259, jan./jun. 2015. Disponível em: <http://www.sbsociologia.com.br/revista/index. php/RBS/issue/view/9>. Acesso em: 20 dez. 2016.

SARTI, Cynthia. A ética em pesquisa transfigurada em campo de poder: notas sobre o sistema CEP/Conep. Revista Brasileira de Sociologia, Brasília, v. 3, n. 5, p. 77-96, jan./jun. 2015. Disponível em: <http://www.sbsociologia.com.br/revista/index. php/RBS/issue/view/9>. Acesso em: 20 dez. 2016.

SOBOTTKA, Emil A. Regulamentação, ética e controle social na pesquisa em Ciências Humanas. Revista Brasileira de Sociologia, Brasília, v. 3, n. 5, p. 51-77, jan./jun. 2015. Disponível em: <http://www.sbsociologia.com.br/revista/index. php/RBS/issue/view/9>. Acesso em: 20 dez. 2016.

UNESCO. División de Ética de la Ciencia y la Tecnología. Sector de Ciencias Sociales y Humanas. La ética de la ciencia y tecnología en la Unesco. Paris, 2008. Disponível em: $<$ http:// unesdoc.unesco.org/images/0016/001600/160021s.pdf>. Acceso em: 20 jan. 2016.

ZALUAR, Alba. Ética na pesquisa social: novos impasses burocráticos e paroquiais. Brasília, v. 3, n. 5, p. 133-157, jan./jun. 2015. Disponível em: <http://www.sbsociologia.com. br/revista/index.php/RBS/issue/view/9>. Acesso em: $20 \mathrm{dez}$. 2016.

Recebido em 01-06-2017. Aprovado em 19-07-2017. 